I have insisted. To give more only were to indulge in useless digression and vain repetition. They are most of them very brief, simply because the treatment proved rapidly successful. Let me also add, that while the one essential line of treatment was carried out in each case, some other agents were used incidentally for incidental symptoms, such as must ever occur in so complicated a structure as the human body ; but none of them so as to influence, or at least invalidate, the main plan.

CASE I. Mr. A. H. first consulted m? on 23rd April, 1855. He had been for unwards of two months troubled with a succession of large hard boils, which had been poulticed, and opened again and again; whilst his bowels had been acted upon by saline cathartics. Under this system they continued to reappear. I advised a continuance of the poultices, and the use of the lancet to existing boils; and prescribed for internal use, ten grains of the iodide of potassium, with two drachms of Huxham's tincture of bark, and half a drachm of tincture of hyoscyamus, three times a day.

On May 3rd, all the boils were rapidly healing up, except a very large one, which was treated by iodine applications. No fresh ones had shown themselves; but there was a profuse eruption of little pustules over the skin, such as is ordinarily caused by the iodide. Its further use was therefore stopped, and he had the tonic tincture as before, with muriate of morphia, and muriatic acid.

May 10th. He was proceeding favourably, with no further eruptions.

May $17 \mathrm{th}$. He was quite well, with only a little hard swelling over the seat of the large boil. I can attribute the speedy arrest here only to the bark and its adjuncts.

CASE II. E. W. was seen by me on Oct. 13 th, 1856 . $\mathrm{He}$ was a delicate young lad of smoky unhealthy com. plexion, thin and weakly. Some time before, he had injured a finger, and a severe whitlow was the result. From his timidity, the opening of this whitlow had been delayed, and when the opening was effected, the wound was offensive, and would not heal; but, in addition, there had appeared on various parts of the hody, dark hard boils, which were very piainful. At this time, the bone of the finger was necrosed, and its removal was advised, as well as the opening of those boils that were pointing.

His bowels being very mnch eonfined, he took two drachms of compound tincture of senna every night; and three grains of iodide of potsssium, with a drichm of compound tincture of bark, and four drops of tincture of opium, thrice a day.

By the 20th, the finger was healing, as well as the boils that had been opened, and no fresh outbreak of the kind occurred. He subsequently took the bark with sulphuric acid, and regained his usual health. Here, I think, we have, in regular succession, carious abscess-absorption of putrid particles into the blood of an already sickly subject-production of boils, and their arrest by the treatment.

[To be continued.]

The Dublin Medical Schoors. There are 806 Students of Medicine and Surgery attending Lectures and Hospitals in Dublin this winter; 1,237 Students in London; and 1,156 in Paris-being a larger number than is usual in all three capitals. The Students of Medicine in Dublin 1860-61, are divided among the various Schools as follows:-The Ledwich School, 228; College of Surgeons' School, 220; Cecilia-street School, 101 ; Trinity College School, 100; Richmond Hospital School, 97; Steevens' Hospital Sclıool, 60; total, 806. Of the 101 Students attending the Trinity College School, 80 are Graduates or Undergraduates in Arts. (Dublin Hospital Gazette.)

\section{ON THE OCCURRENCE OF DEPOSITS OF CRYSTALLISED PHOSPHATE OF LIME IN HUMAN URINE.}

By Wimlanir Roberts, M.D., Physician to the Manchester Royal Infirmary.

Dr. Hassat.r, seems, so long ago as 1852 , to have satisfied himself that phosphate of lime appeared occasionally in urine in a crystalline state; for, in his little work on the urine, the eighteenth plate contains a delineation of "crystals of phosphate of lime," and the date appended to the drawing is August 1852.

In the beginning of last year, Dr. Hassall read a paper before the Royal Society, "On the Composition and Pathological Importance" of the calcareous phosphates occurring in the urine as a spontaneous deposit of stellar crystals. He found these crystals to consist of biphosphate of lime; he also considered them of more frequent occurrence and of far graver signification than the triple phosphate of ammonia and magnesia.

My attention had been directed to these crystals with curiosity for some years; and recently $I$ have had an opportunity of subjecting them to chemical analysis. Before the pullication of Dr. Hassall's observations they were universally considered to have the same composition as the prismatic phosphate, which contains am. monia and magnesia, but no lime; and it was believed that the phosphate of lime never assumed the crystalline state in urine, but was always deposited as an amorphous sediment.

The forms of the crystals in question present con. siderable variety; but they are, nevertheless, easily recognised by the practised eye. Good figures of them are given by Dr. Beale in his twenty-second plate, although erronenusly designated "A Rare Form of Triple Phos. phate": still better ones have been published by Dr. Hassall in the little work already alluded to ; also in the Lancet for 1857 , as well as in the paper communicated by him to the Royal Society, January 1860.

Dr. Bird had evidently seen these crystals, and he gives imperfect figures of them. (Fig. 45.) He held them to be of the same composition with the triple phosphate.

In the atlas accompanying Lehmann's Physiological Chemistry, Funke gives two capital plates in lis twelfth plate, but he names them uric acid.

The prevailing appearance is that of crystalline rods or needles grouped round a centre, so as to form a more or less perfect star. Some of these stars are of great beauty, as large as the finest seen of uric acid, and not unlike them, except in the absence of a brown colour. Sometimes, the rays of the star are so close set that the appearance of a rosette is produced. Again, not unfrequently, the crystals, instead of radiating equally in all directions from the centre, shoot out in one direction only, so as to form a fan; or, in two directions, on opposite sides, so as to present a rude resemblance to a wheat-sheaf. Sometimes, too, the rods lie confusedly across each other, or crystallise round hairs or fibres. Frequently, the rods are wedge-shaped, and thicker at their outer extremity than where they join in the centre. Other forms are club-shaped and bottle-shaped, and abundantly marked with lines of secondary crystallisation, reminding one of the same appearance on the hexagonal plates of cystine.

In a case of diabetes recently under my care, these crystals formed a constant deposit. The urine had been brought down by appropriate treatment to fifty ounces a day, and the patient was steadily gaining strength and flesh. The deposit was often mixed with oxalite of lime, and sometimes with uric acid; but never, except as the result of putrefactive decomposition, with the triple phosphate. I managed to collect about two grains of the crystals in a pure state, unmixed with oxalate of 
lime or triple phosphate, and subjected them to examination, as follows :-

1. Treated with caustic potash they evolved no ammonia; nor were they in any way affected even by boiling in the caustic alkalies.

2. They dissolved slowly in acetic acid without effervescence. On adding oxalate of ammonia to the solution a precipitate fell which, two days after, presented the fumiliar forms of minute octohedra of oxalate of lime. The supernatant liquor, treated with ammonia and phosphate of soda, yielded no precipitate.

3. The mineral acids dissolved the orystals rapidjy, and ammonia added afterwards in excess threw down an amorphous sediment.

They did not lose weight by drying at $212^{\circ}$. When incinerated they lost weight to the extent of twenty-jix per cent.

The first experiment shows the absence of ammonia; and the second shows that the base is lime unmixed with magnesia.

The loss of weight on incineration, in the fourth experiment, is not eritirely due to water. Some of it must be laid to the account of the organic matter entangled in the crystals, which caused them to assume a deep brown colour when burned. Taking this abatement into consideration, the loss of water is about what would take place if the crystals had the same composition as the crystallised phosphate of lime, described by Berzelius as formed when common phosphate of soda is added drop by arop to a solution of chloride of calcium. This salt contains twenty-two per cent. of water, or four atoms, one only of which is basic, the other three being water of crystallisation. On this supposition, therefore, the stellar phosphates have the following formula: $2 \mathrm{CaO}$, $\mathrm{HO}, \mathrm{PO}^{5}+3 \mathrm{HO}$.

By adding a little chloride of calcium to healthy urine, and reducing its acidity to near the neutral point with caustic soda, I have often succeeded in obtaining an abundance of crystals closely resembling those occurring spontaneously in urine. The reaction of the urine, in which I have found the crystallised phosphate of lime has been generally faintly acid, often nearly weutral, and more rarely alkaline from fixed alkali.

The appearance of a crystalline deposit of phosphate of lime in urine is not common. It is, in fact, a rare deposit as compared with oxalate of lime, uric acid, or the amorphous lithates. Dr. Hassall thinks it is more common than the triple phosphate, if decomposed urines be excluded. Practically, however, the reverse is true. Triple phosphate is frequently seen in the urine of the sick, even a few hours after emission, in a multitude of cases where there are none of the ordinary signs of decomposition or putrefaction. Triple phosphate is also very commonly seen in urines made allialine by remedies, after standing a short time.

The presence of the stellar phosphates in quantity is, so far as my experience enables me to judge, an accompaniment of some grave disorder. In addition to the case of diabetes alreedy mentioned, I have seen the stellar phosphates in cancer of the pylorus, once in phthisis, and more than once in patients exhausted by obstinate chronic rheumatism. They may, however, under peculiar conditions, be precipitated in a healthy urine. When the urine is rich in lime, and its acidity is, at the same time, depressed to near the neutral point, stella of phosphate of lime may form quite independently of any grave disorder, merely as the result of a coincidence in the chemical composition and reaction of the urine. For example, after a full meal, the acidity of the urine becomes greatly reduced, and lime derived from the food is in excessive proportion. In such circumstances, I have several time detected stellæ of phosphate of lime, but only in scanty numbers. A depressed acidity of the urine is an essential contingent to the formation of these crystals ; and if the urine, subsequently to their formation, increase in acidity, they may spon- c. taneously disappear.

The persistent occurrence of this deposit in the urine may lead to the formation of stone in the bladder. Calculi of pure phosphate of lime are exceedingly rare, and have quite a different history from the common phosphatic stone of triple phosphate or fusible matter. The latter is always precipitated upon some previous forma- $\mathbb{D}$ tion as a secondary deposit, and is produced by decomposition of the urine. Hence, vesical calculi that have long resided in the bladder, and have been the source of violent and repeated catarrh of that organ, are covered. externally with a phosphatic crust. But the pure phosphate of lime is a primary formation; and, like other $\omega$ primary formations, it may alternate with uric acid or oxalate of lime. There is a beautiful specimen in the museum of the Manchester Infirmary, where phosphate. of lime alternates with pure uric acid. The condition. of urine accompanying a pure phosphate of lime stone $\vec{\omega}$ has not, I believe, been made the subject of direct ob- $\omega$ servation; but one would expect that it would be highly significant of the nature of the concretion. I should expect the following: an urine of pale colour, either feebly acid or alkaliue from fixed alkali (not from am-w monia), with a deposit of stellar phosphates mixed with amorphous phosphate of lime, and absence of triple phosphate and signs of vesical catarrh.

\section{Cramsations of 算ramerthes.}

\section{BATH AND BRISTOL BRANCH}

CASE OF ARM-PRESENTATION WITH EXOMPHALOS.

By J. G. Swaxne, M.D., Physician-Accoucheur to tir Bristol General Hospital, and Lecturer on Midwitery at the Bristol Medical School.

[Read Fcbruary 28th, 1861.]

On October 19th, 1860, $\mathrm{Mr}$. Goodeve requested me to see a patient whom he was attending in a court at the back of the Mall, Clifton, and to whom he was called by one of the midwives of the Clifton Dispensary. He stated that there was a presentation of the elbow, as well as something which appeared to be the umbilical cord and a portion of placenta. I found on my arrival that the membranes had been ruptured for some hours. There had been sorne tritling hæmorrhage, but it had \& produced no constitutional effect. I found, on examination, that the right elbow presented posteriorly, and apparently several coils of funis, quite destitute of pulsation. The pains were but slight. As the os uteri was N pretty well dilated, we decided on the propriety of turn. O ing without delay. Having put the patient under the influence of chlorofurm I passed my hand into the vagina, but found a difficulty in proceeding with the operation in consequence of the large quantity of the supposed cord, which entangled my fingers and impeded the move- $\omega$ ments of my hand. I therefore withdrew my hand, and $\sigma$ at the same time attempted to draw down some of these coils externally. I could not succeed in doing this effectually, but I was able to draw out enough for an $\mathbb{D}$ ocular examination. On looking at some of the sup-? posed cord, by the light of a candle, I found, to my sur- 7 prise, that it was a coil of intestine of a deep port-wine $\vec{D}$ colour, and of such a size that I could hardly suppose $\overrightarrow{\mathbb{D}}$ it to be fuetal. A horrible suspicion immediately tlashed $\bigcirc$ across my mind. Could it be maternal intestine which $\mathbb{D}$ had passed through a rent in the uterus, produced by some clumsy attempts at turning on the part of a midwife? As Dr. Tyler Smith remarks in his Manual of 8 Obstetrics; "In a case of this description huppening to응 a midwife, in which a medical man might be called after 